\title{
The Effect of Computer Simulation in the Development of Metacognitive Skills in Science
}

\section{Samia Saeed Abdulla Baangood}

University of Aden, Faculty of Education, Yemen

\section{Abstract}

This study aimed to investigate the effect of computer simulation in the development of metacognitive skills in science among school students.

The sample of the study was chosen from the seventh-grade students who were divided into two groups, selected randomly to forty two for the experimental group and forty two for the control group, The parity of the two groups was tested according to their scores last year.

To achieve the objectives of this study, the computer simulation program was designed

Corresponding Author:

Samia Saeed Abdulla Baangood

sambaangood@yahoo.com

Received: 18 January 2019

Accepted: 24 March 2019

Published: 31 March 2019

Publishing services provided by

Knowledge E

(c) Samia Saeed Abdulla

Baangood. This article is

distributed under the terms of

the Creative Commons

Attribution License, which

permits unrestricted use and

redistribution provided that the

original author and source are

credited.

Selection and Peer-review under the responsibility of the First ELEHIC Conference Committee.

\section{G OPEN ACCESS}

For Sa unit of science that continued to be applied for a month and a half, according to the model of [1], which had been submitted in 1995 to develop a five-stage multimediaassisted education, and developed in 2002 to suit E-learning technology; The scale that prepared for measurement metacognitive skills, consisted of three parts; planning, monitoring control, and evaluation.

This scale was used for both experimental and control groups, before and after teaching using computer simulation of the experimental group and teaching in the traditional way of the control group.

The results of this study illustrated the importance of the effect of computer simulation in the development of metacognitive skills. This was shown in the presence of statistically significant differences between the experimental and control groups in favor of the experimental group, as well as in the experimental group itself before and after the use of computer simulation as a teaching method. Computer simulation, metacognitive, scale.

\section{Introduction}

The technological revolution that was launched in the world at high speed was the product of the progress of science in our modern world. This scientific technological revolution influenced education and learning, including computer simulation technology and its patterns of use such as virtual reality, artificial intelligence and expert systems 
and the need to benefit from these modern technologies in the development of education and served teacher and learner, which is already reflected on improving the efficiency of the educational process. [2]

Research and studies confirm the advantages of computer use in teaching, such as the study of [3], which found that the use of computers in education, provides the opportunity for practice and training and feedback and promotion, and leads to the motivation and thrill to learn Article.

[4] show that growing scientific progress depends primarily on the mental capacity of the individual, which in turn emphasizes the role of learning to think. The learner can be trained on how to think by teaching the curriculum by providing an environment where learners can understand how they think and how to solve the problems they face, helping them to outline their thinking process, making it easier for them to perform efficiently and demonstrate the ability to analyze, plan, Creatively, in scientific presentation.

As for,[5] mentioned that there is a need for the curriculum to be combined with strategies and teaching methods designed specifically for the development of cognitive thinking. This is what the scholars of education called attention to the study of thinking and teaching through the curriculum and training of students in various skills. Several conferences were held for this purpose, and many studies were conducted internationally, Arab and regional. The most important of these is the Science Curriculum Improvement Study (SCIS) To develop the scientific culture by identifying the basic concepts of natural sciences, developing research and research trends, and using scientific thinking to make decisions [6].

The results of several studies and research have found that cognitive thinking needs to be developed for individuals and emphasize the importance of teaching thinking skills in general, by reconstructing modules in the curriculum that include thinking skills to train students [7].

The development of thinking of various types of the most important objectives of teaching science should be developed in the individual, on the grounds that thinking is a system of interactive knowledge and observable and experimentation and development.To achieve this, science education must focus on helping students acquire the scientific way of thinking or the scientific method of research, and focusing on the methods and processes of science [8]. 


\subsection{Computer simulation programs}

They were used to carry out many experiments, including chemistry experiments for first year students at the University of Canada, and to determine the impact of this on achievement. The results of the study showed that students who used computer simulation learned better than those who studied by traditional method [9].

Another study by [10], was carried out and aimed to identify the effect of strategic use of computerized simulation in the immediate and deferred collection of students in the tenth grade in natural sciences compared to the traditional method, which showed that there were statistically significant differences in immediate and deferred collection for students who used computer simulation.

Also conducted a study aimed at identifying the effectiveness of a proposed simulation program and its effect on achievement in physics and computer orientation. The results of the study showed that the program has an effective effect on the variables (achievement and direction) [11]

Study also Showed the effect of using computer simulation and problem solving on achievement and attitudes towards chemistry compared to traditional methods. The results of the study showed that there were statistically significant differences in the average achievement of the two experimental groups compared to the conventional method. The study showed positive attitudes towards chemistry for the group studied using computer simulation. [12]

Computer Simulation in science teaching Computer Simulation Programs have a clear and important impact on facilitating science education and learning, as they can be used in many areas.

Explanation maybe required for the use of some devices and tools that may not be available at school, inadequate or insufficient, Many things happen and cannot be seen with the naked eye, because of their small size such as atoms and molecules, or temporal or spatial dimensions such as the movement of continents, or they occur at high speed that cannot be followed; such as chemical reactions, or may be slow such as plant growth, gravity to students like preparation of some toxic gases such as chlorine gas [13].

Simulations can also be used when laboratory experiments are costly, or when laboratory experiments cannot be performed in a school laboratory such as the Rutherford experiment [14]. 


\subsection{Metacognitive skills}

Flavell first proposed the concept of metacognition at the beginning of the decade of the 1900s when he presented in his research on memory and metamemory research in the field of evolutionary psychology, through his experiments that revealed that little children are watching Their memories, their understanding and other cognitive matters, and that they have a complete cut in the skills of knowledge beyond.

He defined it as "the ability of the individual to think in his own thinking processes is the knowledge of the individual cognitive processes [15].

"Metacognitive skills aim to monitor and guide cognitive processes used during learning, Therefore, there are many difficulties in the process of assessing these skills as it is difficult to limit the poetic access to the pre-sensory area of automatic or automatic skills and there are effects of social desirability that prevent access to real responses that reflect meta- processes. Many of the tools formulated to measure these skills have come under intense criticism, especially criticism of the validity of these tools.

\subsection{Metacognitive skills classifications}

There is a consensus among large number of researchers on three basic skills of thinking above metacognitive:

1. Planning: [16] defined it as the ability to plan a specific educational activity or task.

2. Monitoring and Controlling: Schwartz and Perkins (2003) identify them as a control of thinking and control in the course of learning, ie, the learner is aware of what he thinks of steps, and has the ability to guide his thinking as planned in advance.

3. Evaluation: [17] stated that evaluation is not only the process of identifying actual results and compared them to results in advance, but also the judgment of two things: the process used to achieve the goal and the outcome of the same process.

\section{Research Design}

The researcher used more than one tool to achieve the objectives of the study, as follows:

1. Computer simulation program.

2. Preparation Scale of Metacognitive Skills. 
3. Preparation of the study plan using computer simulation in the implementation of lessons.

\subsection{Computer simulation program}

It is a model that simplifies the reality by using the computer and it responds to the orders and decisions of the user; gives results similar to what can be applied in practice and aims to give the learner new knowledge and skills through models that mimic the reality presented to students by computer.

The program is designed according to the model of Abdul Latif Al-Jazzar (2002), which was designed to develop Computer-assisted education and e-learning technology, consisting of five stages. It can be applied to a single lesson or unit, [18]. As shown in (Figure1).

\subsection{Metacognitive skills scale}

The Metacognitive Skills Scale is prepared according to the following steps:

1. Review the theoretical framework and previous studies that dealt with the skills of metacognative.

2. The researcher determined dimensions of the scale according to the classification relied on it and consists of the three skills: (planning, monitoring and control and evaluation).

The methods of measuring metacognative are divided into two categories. The first category includes standards that concern the measurement of metacognition in qualitative and specific performance situations, as opposed to another category: measuring metacognition in attitudes Performance generally without attention to a qualitative performance position. [19].

The researcher believes that it is better not to rely on one type of measurement in the measurement of these processes and the use of more than one tool. Therefore, the researcher measured the metacognative skills through the development of activities during the planning and implementation of lessons with the participation of students and through this activity are tested in specific positions are the tasks of solving the activity that reflects the vocabulary of the standard by asking them before starting to resolve the activity, After each activity, it is possible to compare what an individual does by performing his / her activity and what he / she approves through the protocol. In 


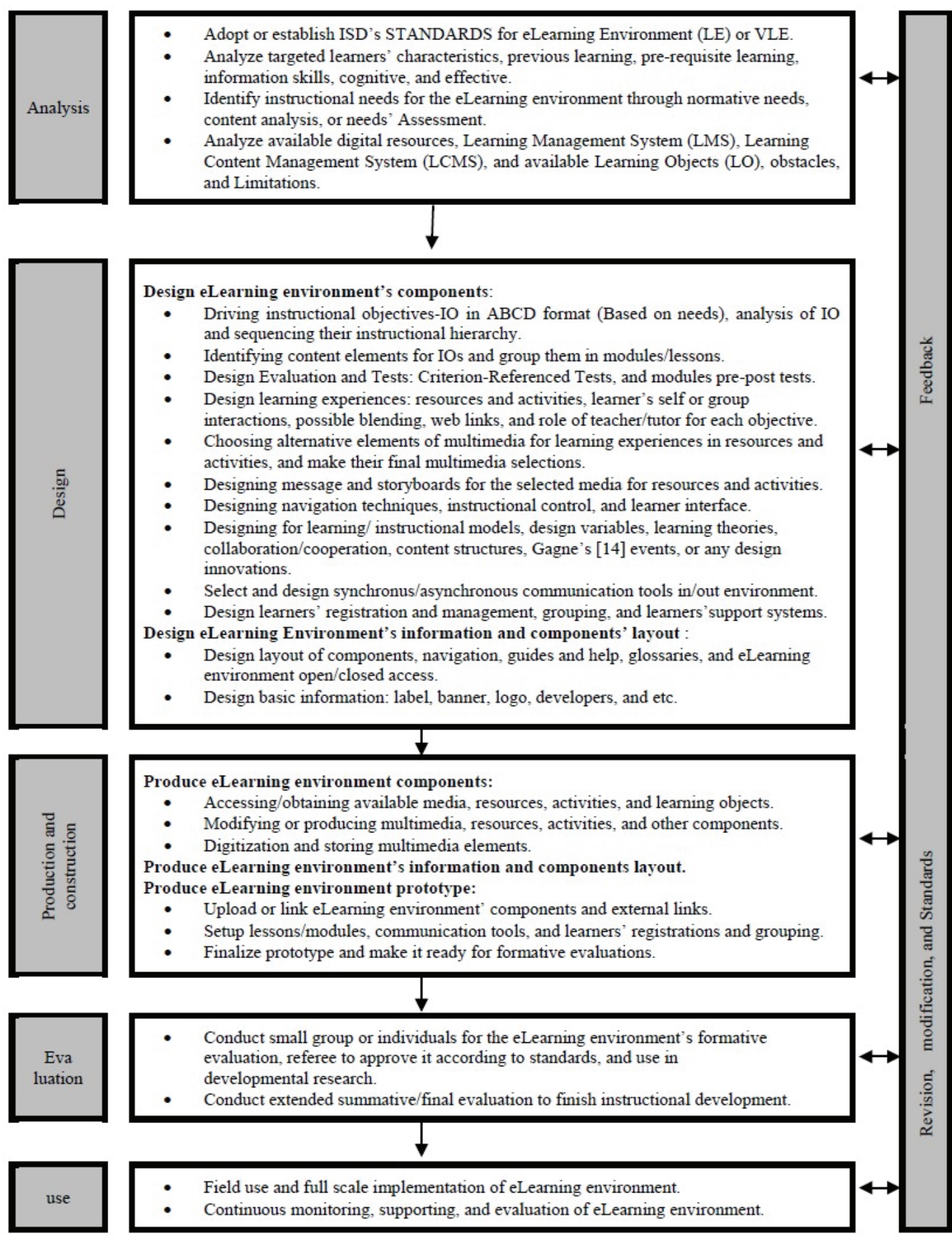

Figure 1: model of Abdul Latif Al-Jazzar (2002).

order to avoid the effects of individual differences in students' expressive abilities. Some students may not be able to describe their actions. Requires answer the student's report of the processes of knowledge that he used to solve this activity and those that did not use which are under study. 


\subsection{Preparation of the study plan using computer simulation in the implementation of lessons}

In view of the importance of the preparation of the study plan, which is a requirement for successful teaching, the researcher prepared the teaching plan for the subjects to be taught to the seventh grade students during the period of the experiment in light of the contents of the science book and the specific objectives of the article; and according to the use of computer simulation

\section{Result and Discussion}

Results of the test of the difference between the experimental and control groups on the Previous-measurement scale of the metacognitive skills of the cognitive thinking in science, are shown in (Table 1):

TABLE 1: The results of the use of the pre- Metacognitive skills scale.

\begin{tabular}{|l|l|l|l|l|c|}
\hline Axis / scale & groups & mean & $\begin{array}{c}\text { standard } \\
\text { deviation }\end{array}$ & $\begin{array}{c}\text { Calculated } \\
\text { value }\end{array}$ & P-value \\
\hline Planning & Experimental & 3.1190 & 0.96783 & 0.552 & 0.582 \\
\hline & Control & 3.2381 & 1.00752 & & \\
\hline Control and control & Experimental & 6.9286 & 2.57940 & 0.444 & 0.658 \\
\hline & Control & 6.6905 & 2.33205 & & \\
\hline Evaluation & Experimental & 3.8095 & 1.48551 & 0.454 & 0.651 \\
\hline & Control & 3.9524 & 1.39603 & & \\
\hline $\begin{array}{l}\text { post-measurement scale of } \\
\text { the metacognitive skills }\end{array}$ & Experimental & 13.8571 & 4.22866 & 0.222 & 0.825 \\
\hline & Control & 14.0476 & 3.59507 & & \\
\hline
\end{tabular}

Results show that there is a significance of the difference between the experimental and the control groups on the post-measurement scale of the metacognitive thinking skills in science,as shown as (Table 2):

Table 1 shows that there are no statistically significant differences between the experimental and control groups in the Metacognitive skills scale for; planning, monitoring, control and evaluation skills, as well as in the pre-Metacognitive skills scale in general, which confirms the equivalence of the two groups before teaching the unit.Table 2 shows that there is a statistically significant difference at 0.05 between the experimental and control groups and for the experimental group in the planning, monitoring, control and assessment skills as well as in the post- of the metacognitive skills scale in general. 
TABLE 2: Results of the use of the post- Metacognitive skills scale.

\begin{tabular}{|c|c|c|c|c|c|}
\hline Axis / scale & groups & mean & $\begin{array}{l}\text { standard } \\
\text { deviation }\end{array}$ & $\begin{array}{l}\text { Calculated } t \\
\text { value }\end{array}$ & P-value \\
\hline \multirow[t]{2}{*}{ Planning } & Experimental & 5.5952 & 1.36256 & 6.508 & 0.00 \\
\hline & Control & 3.7381 & 1.25055 & & \\
\hline \multirow[t]{2}{*}{ Control and control } & Experimental & 11.0238 & 2.76289 & 6.431 & 0.00 \\
\hline & Control & 7.0952 & 2.83540 & & \\
\hline \multirow[t]{2}{*}{ Evaluation } & Experimental & 5.9048 & 1.28423 & 5.658 & 0.00 \\
\hline & Control & 4.0476 & 1.69580 & & \\
\hline \multirow{2}{*}{$\begin{array}{l}\text { post-measurement scale of } \\
\text { the metacognitive skills }\end{array}$} & Experimental & 22.5238 & 4.65512 & 8.623 & 0.00 \\
\hline & Control & 14.6667 & 3.63363 & & \\
\hline
\end{tabular}

This finding can be attributed to the fact that teaching the audio unit "using computer simulations and using learning and learning activities to develop knowledge-based thinking skills (planning, monitoring, control and evaluation), as indicated by the results of students' averages in the metacognative skills scale, This confirms that the computer simulation method used for experimental group students has contributed to the development of these skills.

Effective participation in organizing the steps of using the computer simulation program and controlling these steps from start to finish helped students deal with educational situations and interact with and organize information, which in turn contributed to the development of thinking skills beyond the knowledge of (planning, monitoring, control and evaluation).

This result is on line with the findings of [20], and [21], that teaching in computer simulations has helped to develop the cognitive skills of students in the experimental group, as well as the study of [22] of the effectiveness of teaching in computer simulation.

\section{Conclusion}

Based on the results of the study and the use of computer simulations in the design of science courses to develop knowledge skills, the researcher reached the following conclusions:

1. The use of the computer simulation method allowed the students to participate positively and effectively and not limit their role as recipients only. 
2. The lesson planning was computer simulation learning and learning activities included metacognative skills that enhanced learning content, helped develop these skills and led to higher educational attainment.

3. Using the skills of metacognitive in lesson planning has an impact on raising the mental capacity of the students' knowledge and learning skills.

4. Using computer simulations and metacognitive skills activities help students recall their past experiences, identify what they wanted to learn, and make them active and positive in learning.

\section{References}

[1] Al-Jazzar, Abdel-Latif Ben-Safy (1999): Introduction to Educational Technology (Theory and Practice), Cairo, Author, Girls College, Ain Shams University, 81. (in Arabic)

[2] Tawfiq, Salah al-Din Muhammad (2003). Simulation and educational development. Journal of the Future of Arab Education, Research Arbitrator. vol 9, issue no. 29,pp 246.(in Arabic).

[3] Al-Haila, Mohamed (1998): Technology of Learning between Theory and Practice, 1, Amman, Jordan: Dar Al-Masirah for Publishing, Distribution and Printing. (in Arabic)

[4] Laqani, Ahmed and Fara'a, Hassan (2001): Curriculum between reality and the future, 56 , Cairo, the world of books.

[5] Al'aesar, safa' yusif (1998): Education for Thinking, Cairo, Dar Quba,66. (in Arabic).

[6] Gardner,H.(1999): Intelligences reframed Multiple Intelligences for the 21st century. New York: Basic Books, 12.

[7] Swartz, R., \& Perkins, D. N., 1989. Pacific Grove, CA: Midwest Publications.

[8] Zeitoun, Aish (1999): Methods of Teaching Science, First Edition, Amman: Dar Al Shorouk Publishing and Distribution. 94.(in Arabic).

[9] Kennepohl, D. (2001). Using computer simulations to supplement teaching laboratories in chemistry for distance delivery. Journal of Distance Education, vol 16 issue no. 2, pp58-65.

[10] Alissa, Adel Musa Mohammed. (1993). The impact of the use of simulation strategy implemented through the computer assistant in the immediate and deferred collection of students in the tenth grade basis in natural science. Unpublished master thesis. University of Jordan: Jordan.(in Arabic). 
[11] Okey, J. R. \& Oliver, R. G. (1987). Learning From Computer Simulation, Paper Presented at Annual Meeting of the National Association for Research In Science Teaching, Washington D.C., April, 1987,3-18.

[12] Geban, Omer.(1992). Effects Of computer simulations and problem solving Approaches on High school Student, Journal of Educational Research, vol. 86, issue no. 1, pp 5-10.

[13] Al-Far, Ibrahim Abdul-Wakil. (2002). Computer use in education. Amman:Dar Al Fikr for Printing, Publishing and Distribution.(in Arabic).

[14] Tawfiq, Salah al-Din Muhammad (2003). Simulation and educational development. Journal of the Future of Arab Education, Research Arbitrator. vol 9, issue no. 29,pp 246.(in Arabic).

[15] Flavell, H.J. (1979). "Metacognition and Cognitive Monitoring" A New Area of Cognitive Developmental Inquiry", American Psychologist. vol. 34 issue no.10, pp. 906-911.

[16] Al Ruwithi, Iman Mohamed Ahmed (2009): A New Vision in Learning Teaching from a Cognitive Thinking Perspective, (I 1), Dar Al Fikr Publishers and Distributors, Amman, Jordan.24(in Arabic).

[17] Jarwan, Fathi (2002): Creativity. Amman, Jordan: Dar Al Fikr for Printing and Publishing, 35

[18] Al-Jazzar, Abdullatif Ben-Safi (2002): "The Effectiveness of Using MultimediaAssisted Learning in Acquiring Some Levels of Learning of Scientific Concepts according to Frayer's Model for Evaluating Concepts, Journal of the Faculty of Education, Al-Azhar University, pp 60, 105. (in Arabic)

[19] Amer,Ayman Mohamed (2002): "The Effect of Awareness on Creative Processes and the Creative Method of Problem Solving", unpublished PhD thesis, Faculty of Arts, Cairo University..(in Arabic).

[20] Abu Al-Saud, Hani (2009): A technical program based on simulation to develop some of the skills of knowledge in the curriculum of science students in the ninth grade in Gaza, MA (published), Faculty of Education, Islamic University - Gaza..(in Arabic).

[21] Al-syd, hamat eatiat qasim (2007): The Effectiveness of High Methods of Achievement and the Achievement of Students in Educational Technology Some of the Skills of Transcendental Thinking (unpublished Master Thesis), Faculty of Specific Education, Ain Shams University, Egypt.

[22] Abu Madi,Sajeda Kamel Ahmed, 2011: The Effect of Using Computer Simulation on the Acquisition of Concepts and Electrical Skills in Technology for Grade 9 Students 
in Gaza, Master Thesis, Faculty of Education, Islamic University of Gaza Published at http://library.iugaza.edu.ps/hesis/98861.pdf 